\title{
38 \\ Rights Dialogue under the Victorian Charter: The Potential and the Pitfalls
}

\author{
Julie Debeljak ${ }^{1}$
}

\section{Introduction}

The Charter of Human Rights and Responsibilities Act 2006 (Vic) was intended to create an inter-institutional dialogue about rights. This chapter outlines the Charter's dialogue mechanisms, and assesses the dialogue in practice. The assessment focuses on examples of institutional dialogue that have involved judicial decisions about rights or with rights implications, and executive and parliamentary reactions thereto. This chapter concludes with reform suggestions for the Charter, which can inform debates across Australian jurisdictions.

Committed parliamentary sovereigntists may consider that the Charter is operating precisely as intended: bringing rights issues to the fore, and providing a framework for debate, but not substantively hampering the sovereign will of parliament. Those committed to human rights, however, may consider the dialogue in practice demonstrates the need for reform. In decision-making that impacts on rights, the executive retains its dominance: it controls the 'pre-tabling-in-parliament' phase of legislative

1 Associate Professor and Deputy Director of the Castan Centre for Human Rights Law, Faculty of Law, Monash University. 
development; shapes the rights discussion via extrinsic materials accompanying proposed legislation; and dominates parliament itself. Contributions by members of parliament to rights dialogue on the floor of parliament and through its committees are weak, with little incentive for stronger action. Parliamentary rights culture is nascent at best, and there is no political or legal cost for disregarding rights. The judiciary has the limited power of interpreting laws to be compatible with rights, which leaves the executive and parliament free reign in their responses. Reforms must focus on these elements.

\section{Dialogue Mechanisms}

There are numerous dialogue mechanisms under the Charter. First, the scope of rights, and the legitimacy of limiting rights, are open to debate and reasonable disagreement. The Charter recognises this through open-textured rights, and by allowing the imposition of reasonable and demonstrably justifiable limitations on rights under $\mathrm{s} 7(2)$ - both of which encourage rights dialogue among the executive, parliament and judiciary.

Second, Charter mechanisms regarding the creation and interpretation of legislation are meant to generate dialogue. Under s 28, parliamentarians must issue Statements of Compatibility (SoC) for all proposed laws, which indicate (with reasons) whether proposed laws are rights-compatible or rights-incompatible. Under s 30, the Scrutiny of Acts and Regulations Committee (SARC) must scrutinise all proposed laws and accompanying SoCs against Charter rights. SARC reports to parliament, and parliament debates the proposals, deciding whether to enact proposed laws given the rights considerations.

These pre-legislative scrutiny obligations make rights explicit considerations in law-making, creating greater transparency around, and accountability for, decisions that impact on rights. The obligations also create a dialogue between arms of government, allowing each to educate the other about their understanding of relevant rights, whether legislation limits those rights, and whether limits are justified under s 7(2).

Regarding the judiciary, s 32(1) of the Charter requires all legislation to be interpreted in a way that is compatible with rights, so far as it is possible to do so consistently with statutory purpose. Where legislation cannot be interpreted rights-compatibly, the judiciary is not empowered 
to invalidate it; rather, the superior courts may issue an unenforceable 'declaration of inconsistent interpretation' under s 36(2). Under s 37, the responsible minister must table a written response to s 36(2) declarations in parliament within six-months.

The executive and parliament can respond to judicial rulings. They may neutralise an unwanted s 32(1) rights-compatible interpretation by legislatively reinstating rights-incompatible provisions. They may amend legislation to address rights-incompatibility identified in s 36(2) declarations; equally, they may retain the rights-incompatible legislation. The dialogue process continues, with executive and parliamentary responses being open to further challenge before the judiciary.

To assess these dialogue mechanisms in practice, Part III considers examples of executive and parliamentary responses to judicial decisions about rights; while Part IV considers examples where judicial decisions did not turn on rights, but nevertheless provoked executive and parliamentary responses that did impact on rights.

\section{Complete Dialogue Cycles}

A 'complete dialogue cycle' occurs when each arm of government has contributed to the rights dialogue; particularly, when the executive and parliament respond to judicial decisions about rights. This Part explores two examples where judicial decisions turning on rights have prompted executive and parliamentary responses that have been rights-unfriendly. ${ }^{2}$

\section{A. Decisions and responses}

First, under the Serious Sex Offenders Monitoring Act 2005 (Vic), a court may make an extended supervision order in relation to serious sex offenders 'if it is satisfied ... that the offender is likely to commit a relevant offence if released in the community on completion of' a custodial sentence. In $R J E,{ }^{3}$ the court held that the phrase 'is likely to commit a relevant

2 See Taha v Broadmeadows Magistrates' Court [2011] VSC 642, where the representative response bolsters rights: s 51 of Sentencing Amendment (Abolition of Suspended Sentences and Other Matters) Act 2013 (Vic).

3 RJE $v$ Secretary to the Department of Justice [2008] VSCA 265 ('RJE). 
offence' had to mean 'more likely than not to commit' an offence, ${ }^{4}$ with Maxwell $\mathrm{P}$ and Weinberg JA relying on the common law right to liberty, and Nettle JA relying on the s 21 right to liberty and s 32(1) rightscompatible interpretation under the Charter.

At the next sitting, parliament responded by overturning the rightscompatible interpretation in RJE. The Serious Sex Offenders Monitoring Amendment Act 2009 (Vic) (SSOMAA) inserts s 11(2B), which states that s 11(1) 'permits a determination that an offender is likely to commit a relevant offence on the basis of a lower threshold than a threshold of more likely than not'.

Second, the Major Crime (Investigative Powers) Act 2004 confers coercive powers for investigating organised crime. Section 39(1) abrogates the privilege against self-incrimination, but $s$ 39(3) provides a residual immunity. In Das, ${ }^{5}$ according to ordinary interpretation, Warren CJ held that s 39(3) only preserved 'direct use' immunity, which unreasonably and unjustifiably limited Charter rights. This was remedied by s 32 rights-compatible interpretation: Warren CJ 'read in' words to s 39(3) additionally preserving 'derivative use' immunity.

Parliament reversed this ruling in the Criminal Organisations Control and Other Acts Amendments Act 2014 (Vic) (COCOAAA). The legislation inserted s 39(4), which provides that nothing in s 39(3) prevents the derivate use of evidence.

\section{B. Executive and parliamentary scrutiny}

The rights-scrutiny in the executive's SoC was similar in RJE-SSOMAA and Das-COCOAAA. In both instances, the minister admitted to reversing the judicial interpretation of legislation and reverting to the legislation's preCharter understanding. In both, this was justified as a reassertion of the intention of the original parliament when it enacted the original law. Additional arguments about the reasonableness and justifiability of the limitation were also offered.

4 RJE [2008] VSCA 265 [21], [53] (Maxwell P and Weinberg JA); [97], [107], [113], [117], [119] (Nettle JA).

5 Re Application under the Major Crime (Investigative Powers Act); Das v Victorian Equal Opportunity and Human Rights Commission 2004 [2009] VSC 381 ('Das'). 
SARC reported on RJE-SSOMAA after the amendments passed both houses of parliament. The report criticised the SoC for not explaining how the legislation was rights-compatible. The SARC report on DasCOCOAAA highlighted how the SoC limitations analysis differed from the judicial analysis, but acknowledged that parliament was empowered to enact rights-incompatible legislation.

The parliamentary debate on RJE-SSOMAA was brief. Parliamentarians acknowledged the legislative reversal of the judicial interpretation, and the gravity of this. Although concern was expressed about the retrospective application of the amendment, debate focused on balancing the rights of the offender against the rights of victims and the broader community; and on legislative safeguards for the offender. The rights aspects of the DasCOCOAAA amendments attracted little parliamentary attention - there was no debate about the s 39 amendment potentially violating rights, nor that a judicial ruling was being reversed. Ms Pulford described the amendments as 'minor'; ${ }^{6}$ while Ms Pennicuik took issue with other rightsrelated aspects of the legislation, but not the s 39 amendment.

\section{Assessing the dialogue}

In RJE-SSOMAA and Das-COCOAAA, dialogue occurred with the executive and parliament reasserting their views on the threshold for issuing extended supervision orders and 'derivative use' immunity. The representative arms utilised dialogue mechanisms. First, the reasonableness and justifiability of limitations were explored, and the rights of competing groups balanced, under s 7(2). Second, the amendment was couched as reasserting parliament's intention, which is an active factor in s 32(1) rights-compatible interpretation.

In RJE-SSOMAA, parliament completed debate before SARC reported. Although not unlawful, this undermines the dialogue. That SARC identified issues that the parliamentarians had not considered highlights the importance of SARC reports.

In Das-COCOAAA, one interpretation of SARC's commentary on the differing rights analyses of the judiciary and executive is that the Attorney-General should have made a statement of incompatibility. This has conceptual implications. If the Attorney-General simply accepted the

6 Victoria, Parliamentary Debates, Legislative Council, 19 August 2014, 2509 (Ms Pulford). 
judiciary's view of the unjustifiability of the limit, this may be considered 'judge-proofing'/'Charter-proofing' legislation. 'Charter-proofing' refers to the practice where the executive and parliament shape their policy and laws to fit judicial interpretations of rights to avoid adverse court rulings, and this more closely resembles a judicial monologue about rights.

However, tensions arise for democratic accountability if the judiciary and executive put forward competing rights analysis. Were the executive to simply assert an alternative narrative of rights, without acknowledging the competing judicial views and offering reasons for departing from those views, the improved rights-transparency in, and greater rightsaccountability when, law-making that we hope to gain from dialogue is lost. Moreover, where there is a disagreement between the executive and the judiciary, and this is not acknowledged via a statement of incompatibility, parliament is not properly alerted to the disagreement, as occurred in DasCOCOAAA. In that case SARC, the Attorney-General and Ms Pennicuik engaged in rights-dialogue over other amendments, but missed the rightsimplications for s 39 and the reversal of Das.

Finally, SARC's conclusions in Das-COCOAAA were tepid: that the amendments 'may be incompatible' and referral of the issue 'to Parliament for its consideration', 7 despite SARC's analysis suggesting incompatibility.

As examples of dialogue, the Charter allows the executive and parliament to disagree with the judiciary. As examples of rights protection, reasonable people will disagree; but regardless, the Charter elevates parliamentary sovereignty over rights protection.

\section{Executive-Parliament Reactions Impacting on Rights}

Unlike the complete cycles, some judicial decisions that did not turn on Charter rights have nevertheless prompted amendments that did impact on Charter rights. These are explored in this Part.

7 SARC, Alert Digest, No 9 of 2014, 15. 


\section{A. Decisions and responses}

In DPP $v$ Leys, ${ }^{8}$ the court clarified the lawful combination of sentencing options involving community corrections orders, and corrected a drafting error concerning the commencement of interlinked provisions, under the Sentencing Act 1991 (Vic). Parliament codified the judicial decision via amendments, ${ }^{9}$ which were applied retrospectively to ensure that 500 offenders whose sentences may have otherwise been unlawful were deemed to be lawful. Although retrospective application itself is rights-limiting, this was preferred over the rights implications of prospective legislation: being 500 offenders having their rights to liberty, privacy and movement limited because of potentially unlawful sentences.

In Director of Housing $v T K,{ }^{10}$ the Director issued a notice to vacate under s 250 of the Residential Tenancies Act 1997 (Vic) (RTA) because 'the tenant ha[d] used the rented premises ... for any purpose that is illegal'. The notice was ultra vires because in two instances the tenant's drug trafficking occurred in common areas (not the rented premises), and in another the tenant's drug trafficking occurred at the front door which was insufficient to establish 'use' of the rented premises. Amendments to the RTA ensured that drug trafficking on the rented premises or in a common area triggered the 'notice to vacate' power; expanded the power to cover prescribed indictable offences; and changed the trigger for vacation from a police charge to the Director's reasonable belief. ${ }^{11}$ XFJ provides another example. ${ }^{12}$

\section{B. Executive-parliamentary scrutiny and dialogue}

These examples highlight the representative arms' willingness to respond to judicial decisions by enacting rights-limiting legislation. In discharging pre-legislative rights-scrutiny obligations, the representative arms recognised potential violations of rights in all examples, but reasoned away the violation, or justified the violation referring to the competing rights of others, public safety and the like.

8 DPP $v$ Leys [2012] VSCA 304 ('Leys').

9 Road Safety and Sentencing Act Amendment Act 2012 (Vic).

10 Director of Housing $v$ TK (Residential Tenancies) [2010] VCAT 1839 ('TK').

11 Residential Tenancies Amendment (Public Housing) Act 2011 (Vic).

12 XFJv Director of Public Transport [2008] VCAT 2303 led to the Transport Legislation Amendments (Driver and Industry Standards) Act 2008 (Vic). 
In Leys and XFJ, SARC reported after the Bill passed both Houses. In $T K$, SARC directly compared the tribunal ruling with the amendments, challenging the rights-compatibility of the executive-led amendments, to no avail in parliament.

Parliamentary contributions were mixed. In Leys, debate was truncated, with the amendments enacted within 72 hours, and brief parliamentary debate. Debate in XFJ was brief, with the competing rights of the public elevated over individual rights, and parliamentarians lamenting the nonretrospectivity of the amendments (i.e. lamenting the failure to further violate rights). By contrast, debate in $T K$ was relatively sophisticated, with the right to housing considered, the competing rights of other tenants balanced, the impact of the reduced evidentiary burden explored, and legislative safeguards recognised.

\section{Reforms}

These examples demonstrate the need for reform across the dialogue process. During the 'pre-tabling-in-parliament' phase of policy and legislative design, although the executive accounts for rights, this is in secret and there is no guarantee of outside influence. This is problematic because once Cabinet gives 'in-principle' agreement to legislative proposals, it is difficult to secure amendments. If the window for real rights-influence ends at Cabinet, dialogue is nothing more than an executive monologue.

The eight-year Charter review recommends that SoCs be issued with exposure drafts. ${ }^{13}$ This is an improvement, but the examples highlight that rights-impinging legislation is unlikely to be released in exposure draft and likely to be rushed through parliament. Reforms must include: (a) changes to the political culture surrounding amendments in parliament; and (b) an expansion of voices influencing the pre-Cabinetapproval phase of legislative development, with SARC and the Victorian Equal Opportunity and Human Rights Commission being consulted, in confidence, on draft legislation pre-Cabinet-approval.

13 Recommendation 41(b), Michael Brett Young, From Commitment to Culture: The 2015 Review of the Charter of Human Rights and Responsibilities Act 2006 (Victorian Government Printer, Melbourne, 2015) 188. 
SoCs consistently failed to explain 'how' a Bill was (in)compatible. Section 28 must be amended to require consideration of $s 7(2)$ as part of compatibility assessments and evidence-based assessments. Section 28(3) could read: 'A statement of compatibility must state - (a) whether, in the member's opinion, the Bill is compatible with human rights and, if so, how it is compatible by reference to s 7(2) providing evidence for the assessment, and (b) if, in the member's opinion, any part of the Bill is incompatible with human rights, the nature and extent of the incompatibility by reference to 5 7(2) providing evidence for the assessment.'

SARC needs strengthening. First, SARC has two weeks to report on all Bills introduced. SARC reports are often not available before Bills pass either the lower or both Houses. This mutes SARC's contribution to the dialogue. Parliamentarians have suggested that SARC be convened ad hoc whenever 'urgent Bills' are presented to parliament. ${ }^{14}$ In addition, the Charter should be amended to prevent a Bill becoming a valid Act until SARC has reported, and parliament has 'properly considered' the report (see below).

Second, although rights-incompatible analysis and ministerial requests for clarification convey SARC's opinion, SARC's recommendations are mild. This may be consistent with the practice of scrutiny committees, but SARC's current practice 'has had little influence over the content of legislation once the Bill has been presented to Parliament'. ${ }^{15}$ Were SARC privately consulted on proposed legislation before Cabinet approval, the executive might be induced to present more rights-compatible Bills. SARC's public reports could then be frank rights assessments with (stronger) conclusions (particularly where SARC's private concerns are not addressed).

Parliament must develop and nurture a rights culture, ensuring there is a political cost for not protecting rights and not convincingly justifying limitations on rights. Non-legal methods of cultural change include: (a) developing strong leadership supportive of a rights-respecting culture (top-down approach), and identifying non-senior parliamentarians to act

14 Victoria, Parliamentary Debates, Legislative Council, 16 August 2012, 3535 (Mr Pakula) and 3541 (Ms Pennicuik).

15 Above n 13, 177, citing the Chair of SARC, Carlo Carli MP. 
as change agents among the parliamentary cohort (bottom-up approach); ${ }^{16}$ (b) better education about the substance of rights and the proportionality analysis informing limitations to rights, and education about the process of rights-scrutiny and how it feeds into the inter-institutional dialogue; and (c) pressure from constituents.

Legal methods include imposing an obligation on parliament to 'give proper consideration' to SoCs and SARC reports, with a failure to give proper consideration precluding a Bill becoming an Act. In relation to SARC, s 30 should become s 30(1), with: subs (2) preventing parliament enacting laws prior to SARC reporting; subs (3) requiring parliament to give 'proper consideration' to SARC reports; and subs (4) stating 'a failure to comply with sub-sections 30(1), (2) and (3) prevents that bill becoming an act, and any purported act is not valid, has no operation and cannot be enforced'.

Parliament needs costs/consequences for rights-incompatibility, which presents a multifaceted problem. First, unlike the Canadian Charter, the Victorian Charter is not a constitutional instrument, so the judiciary cannot invalidate rights-incompatible legislation. The latter Charter is a statutory instrument similar to Britain's, but unlike Britain - which has a stronger parliamentary rights-culture - there is no oversight by a regional human rights court that issues binding decisions. The threat of constitutional invalidation (Canada) or enforceable regional decisionmaking (Britain) focuses the mind of parliamentarians.

Second, judicial decision-making under the Charter has been weak. Section 32 rights-compatible reinterpretation as a remedy has been undermined and the role of $s$ 7(2) is uncertain $;{ }^{17}$ judicial decisions on rights have been timid; ${ }^{18}$ and some judges have questioned the dialogue

16 Bronwyn Naylor, Julie Debeljak and Anita Mackay, 'A Strategic Framework for Implementing Human Rights in Closed Environments: A Human Rights Regulatory Framework and its Implementation' (2015) 41 Monash University Law Review 218, 265-66.

17 Julie Debeljak, 'Who Is Sovereign Now? The Momcilovic Court Hands Back Power Over Human Rights That Parliament Intended It To Have' (2011) 22 Public Law Review 15-51; Julie Debeljak, 'Proportionality, Rights-Consistent Interpretation and Declarations under the Victorian Charter of Human Rights and Responsibilities: The Momcilovic Litigation and Beyond' (2014) 40 Monash University Law Review 340-88.

18 Julie Debeljak, 'The Rights of Prisoners under the Victorian Charter: A Critical Analysis of the Jurisprudence on the Treatment of Prisoners and Conditions of Detention' (2015) 38 University of New South Wales Law Journal 1332-85. 
conception. ${ }^{19}$ Recommendations to strengthen ss 32(1) and 7(2) in the eight-year Charter Review, if adopted, should improve the judicial - and thus parliamentary - engagement with rights. ${ }^{20}$

\section{Conclusion}

The Victorian executive dominates the debate about rights, both in the pre-tabling and parliamentary phases of law-making. This dominance is not ameliorated by parliament or the judiciary, due to limitations under the Charter and cultural approaches to rights. The executive dominance of parliament, at least of the lower house, converts what would be an ideal, three-way 'rights-multilogue' into a two-way rights-dialogue between the executive and judiciary. (Indeed, the debate between constitutional and statutory instruments is better cast as one between judicial versus executive monopolisation of rights.) Without breaking the executive's dominance or adopting a constitutional instrument, an executive-dominated rightsmonologue, coupled with parliamentary and judicial rights-heckling, is what remains.

19 HCA Momcilovic [2011] HCA 34, [95] (French CJ), [146] (Gummow J, Hayne J concurring),

20 Recommendations 28 and 29: above n 13, 137-55. 
This text is taken from New Directions for Law in Australia: Essays in Contemporary Law Reform, edited by Ron Levy, Molly O’Brien, Simon Rice, Pauline Ridge and Margaret Thornton, published 2017 by ANU Press, The Australian National University, Canberra, Australia. 